\title{
Factors Determining First Birth Age at East Jawa Province
}

\author{
Achmad Sjafii, Doris Padmini Selvaratnam, Nadya Anita Rahmi, Imroatul Mubarokah
}

\begin{abstract}
Findings of the Indonesia Demographic and Health Survey (IDHS), 2017 demonstrate that the women's age of first birth in East Jawa is at the 8th highest after Provinsi D.I. Yogyakarta, Kepulauan Riau, Banten, Aceh, Sumatera Utara, Nusa Tenggara Timur and Jawa Tengah. This is attributed to pre-marital sex, early marriage and teenage marriages. Teenage pregnancy poses medical risks compared to adult pregnancy. Income and ability to provide medical care for baby has influenced fertility rate. The higher the income, the lower the fertility rate. Education and fertility rate is also negative, whereby the higher the education level of a woman, the age of first birth increases. This study looks at the demographic and socio-economic factors that influence age of first birth. The cohort age of the women studied are 15-24 years and residing at East Jawa. Quantitative and cross-sectional data analysis method is used to analyse the Indonesia Demographic and Health Survey of 2017. Statistics tests were run to produce frequencies, descriptive and inferential analysis. Findings show that first birth age is at 19.36 years, divorced, have 2-3 children and age of first sex is 14 years, primary educated, unemployed, poor, living in rural area and never migrated. Policy implication of this study are (a) acceleration and spread of information on "Reproductive Health" for adolescents, especially in the targeted areas of "Family Planning Kampong" in rural areas, (b) improve friendly service to invite young married women to use contraceptive devices, (c) increase and disseminate information through new entrepreneurial groups to adolescents in poor region.
\end{abstract}

Key words: first birth age, SDKI 2017, demography, socio-economics.

\section{INTRODUCTION}

\section{BACKGROUND}

Findings of Indonesia Demographic and Health Survey (IDHS) 2017 shows that the first age of giving birth for women in East Java was ranked in the top eight after Province D.I. Yogyakarta, Riau Islands, Banten, Aceh, North Sumatra, NTT and Central Java. The main cause of birth in adolescence due to having a pre-marital pregnancy so that early marriage occurs and the first age of childbirth is getting younger. Married women tend to be pregnant at the age of

Revised Manuscript Received on November 11, 2019.

* Correspondence Author

Achmad Sjafii, Doctorate candidate at Universiti Kebangsaan Malaysia.achmadsjafii@gmail.com

Doris Padmini Selvaratnam, Doctorate in sociology and is an Associate Professor at Faculty of Economics and Management, Universiti Kebangsaan Malaysia.pegasus@ukm.edu.my

Nadya Anita Rahmi, Doctorate in sociology and is an Associate Professor at Faculty of Economics and Management, Universiti Kebangsaan Malaysia.nadiafun@gmail.com

Imroatul Mubarokah3, Graduate of Faculty of Economics and Business, Airlangga University, Indonesia. iimroatu120@gmail.com

adolescents, so they have a greater risk than women who are pregnant at an older age. Early marriage has a very complex impact on all aspects of life, one of which is closely related to the first birth in adolescence. Young women who give birth before 15 years of age are 5 times more likely to die during childbirth than women aged 20 years and over (UNICEF, 2008)

Early marriage is one of the initial causes of the start of the reproduction of young women marked by the events of pregnancy and childbirth. The percentage of first marriage age in East Java based on BPS (2018) is quite high, namely in 2017 amounting to 72.94 percent of married women at an early age. The AFM group in the early category in East Java in 2017 is age 15 years (4.94 percent), age 16-18 years (30.56 percent) and age 19-21 years (37.44 percent).

The phenomenon of the first birth of women in adolescence also has an impact on social and economic aspects. This statement is supported by Lloyd et al. (2005) that the implications of social phenomena when adolescents become parents lead to poor careers, such as dropping out of school, low income potential, lower social group status and greater risk of poverty. The condition of adolescence is called a unique transition period with physical and psychological changes that are faced with responsibility for marriage and the presence of children.

Demographic and health aspects also influence first pregnancy in young mothers. Glasier et al. (2005) state that pregnancy at a young age is very risky for miscarriage caused by immaturity of reproductive organs. Rychtarikova et al. (2004) add that the effects of age at first birth in adolescence can be assessed by the following five specific factors: 1) unhealthy mother and baby, 2) increase in fertility, 3) miscarriage, 4) chromosomal abnormalities, 5) complications of hypertension, and 6) death of mother and child. Adolescence is part of a special period of maturation of the human reproductive organs that is still growing or maturing is not ready for child-bearing functions.

McLanahan (2004) states that according to the perspective of resource allocation, children born to younger mothers experience huge losses compared to children born to older mothers. The case requires a deeper analysis of the condition of the first age giving birth to women aged 15-24 in terms of demographic, social, economic, regional and migration characteristics. The aim of the study was to analyze the first age demographic, socio-economic factors giving birth for women aged between 15-24 years in East Java Province based on the 2017 IDHS. 


\section{Factors Determining First Birth Age At East Jawa Province}

\section{THEORECAL BACKGROUND}

Davis and Blake (1956) state that the high and low fertility of a country is influenced by intermediate variables which are classified into sex relations variables, conception variables and gestational variables. Each intermediate variable has a positive and negative relationship in influencing fertility. The variable between Davis and Blake related to reproduction consists of 11 variables which are grouped into three stages of the reproductive process, namely:

I. Factors that influence the likelihood of intercourse variables

II. Factors that influence the likelihood of conception.

III. Factors that affect pregnancy and birth (gestation variable)

1. Fetal mortality caused by accidental factors.

2. Fetal mortality by intentional factors.

a. Sociology expert Freedman (1975) developed an intermediate variable that explained the differences in fertility in Davis and Blake's Theory. The intermediate variable is closely related to social norms that develop in the community. Social norms affect the progress of married couples in behaving related to the birth process from marriage, pregnancy to childbirth. The number of children who can be accepted in the community shows the values and norms about children's values that apply in the community. Bongaarts (1978) explains that socio-economic, cultural, and environmental variables will affect fertility through intermediate variables which have a direct influence on fertility. Bongaarts also summarizes the 11 intermediate variables proposed by Davis and Blake into eight factors grouped into three broad categories including:

I. Exposure factor (Exposure factor)

(1) Marriage

II. Intentional fertility control factor

(2) Use of contraception, (3). Induced abortion (intentional abortion)

III. Natural fertility factor

(4) Lactation, (5) Frequency of sexual intercourse, (6) Sterility (not including contraceptive sterilization), (7) Spontaneous intrauterine death (stillbirth / fetal death), and (8) Duration of the fertile period

Of the eight intermediate variables, Bongaarts concluded that there were only four factors (intermediate variables) that played a major role in fertility, namely marriage, contraception, lactation (breastfeeding) and abortion. In most societies, women spend most of their potential reproductive years from marriage so that the number of live births is higher in married women because they can have sexual intercourse regularly. Conversely, the use of contraception will reduce fertility because it can delay the occurrence of conception. Similarly, intentional abortion makes ovulation faster when compared to women who maintain their pregnancy while lactation has an inhibiting effect on ovulation which increases birth intervals and reduces natural fertility.

Leibenstein's theory views children in terms of utility for the economic transfer of parents and the cost of caring for children. When parents' income increases, parents prefer a little quality children by sending their education to higher education, including tutoring and courses that cost a lot. As a result, the aspect of usability helps reduce parents. If the cost

of raising a child is greater than its usefulness, there is a decrease in the demand for children, and vice versa.

Gary Becker's theory analyzes the influence of income levels and the cost of caring for children on fertility levels. The relationship between income level and fertility level is negative. Gary Becker disproves the theory of the allocation of time which views children as inferior goods. When income increases, the time and costs incurred are increasingly expensive. In the end, parents prefer little but good quality children.

icroeconomics theory of household fertility explains fertility by the theory of consumer behavior as the basis for analysis with economic principles and optimization in explaining the decision-making process at the family level regarding the desired size of child. Fertility includes the demand for children determined based on rational economic choices. Families who add children must sacrifice the choice of other items, resulting in substitution and income effects. An individual tries to maximize his utility from the consumption of goods or services offered. Under these conditions also experience limited income and relative prices of goods and services produced.

The relationship between income and demand for children is positive. When family income increases, the demand for children will also increase. The relationship between the cost of caring for a child and the desire for other items on a child's request is negative. Mathematically the child's request is as follows:

$$
\begin{aligned}
& \mathrm{Q}_{\mathrm{c}}=\mathrm{f}\left(\mathrm{Y}, \mathrm{P}_{\mathrm{c}}, \mathrm{P}_{\mathrm{x}}, \mathrm{T}_{\mathrm{x}}\right) \\
& \text { whereby: } \\
& \mathrm{Q}_{\mathrm{c}}=\text { Demand for child. } \\
& \mathrm{Y}=\text { Family income level } \\
& \mathrm{P}_{\mathrm{c}}=\text { Net price of child } \\
& \mathrm{P}_{\mathrm{x}}=\text { Price of items other than child } \\
& \mathrm{T}_{\mathrm{x}}=\text { Preference for other items }
\end{aligned}
$$

\section{METHODOLOGY}

This research is a quantitative study with a cross sectional design using secondary data from the results of the 2017 Indonesian Health Demographic Survey (SDKI) in 2017. The study respondents were adolescents aged 15-24 years. Data analysis and statistical tests conducted in this study include descriptive analysis presented in the form of percentage frequency distribution, as well as narrative and inferential analysis.

\section{RESULTS AND DISCUSSION}

\section{a. Conditions of First Age Giving Birth in East Java}

Graph 1 illustrates the percentage of first age giving birth to women aged 15-24 years in East Java. The red graph shows the percentage of women who have experiences in giving birth to adolescence at 22.39 percent. The blue area shows that women who never give birth to adolescence are 77.61 percent. Even so, the percentage of women who have given birth is quite high. 
Percentage of women aged 15-24 who have given birth and have never given birth at a young age (under 25 years)

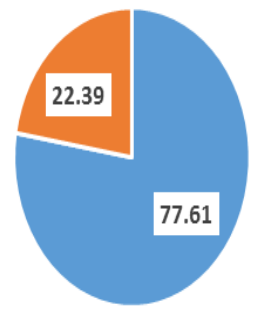

Never given birth before $\quad n \quad$ Given birth befor

\section{Graph 1 First Age Childbirth Age 15-24 years in East Java}

b.Conditions of First Age Giving Birth in East Java National Ranking

The first age average gave birth to women aged 15-24 years in East Java at 19.36. This number is ranked in the top eight nationally. The average age of first childbirth that is above East Java Province includes Province D.I. Yogyakarta (19.84), Riau Islands Province (19.68), Banten Province (19.65), Aceh Province (19.64) and North Sumatra Province (19.62). The average age at first birth in East Java Province is the same as the other three provinces, namely East Nusa Tenggara Province, Central Java Province and Riau Province. For other provinces in Java, East Java Province is ranked third after Province D.I. Yogyakarta.

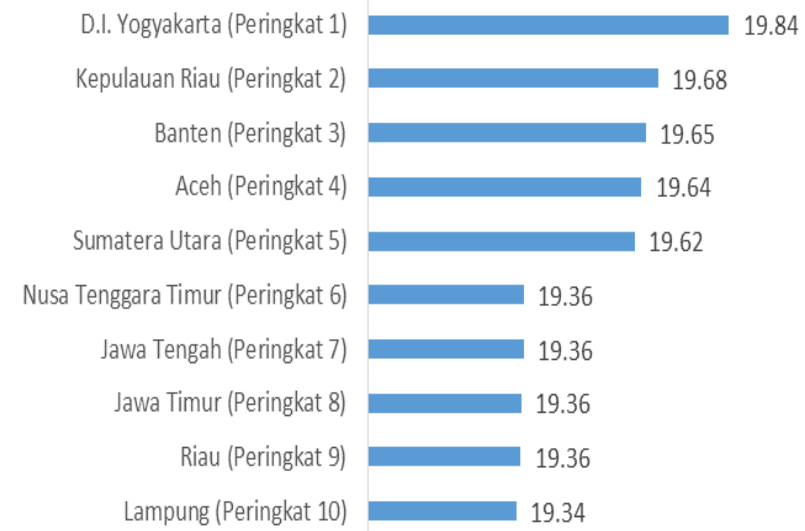

Graph 2 First Age Average Childbirth Based on Top 10 Ranking Nationally

\section{c. Demographic Factor}

Age Group

Graph 3 explains the average age at first birth for women aged 15-24 based on age group. The average age of first childbirth in the age group 15-19 years is 17 years, while the average age at first birth in the age group of 20-24 years is 20 years. This finding shows that the age of older respondents (20-24 years) has the opportunity to give birth first at a younger age than respondents who are younger (15-19 years).

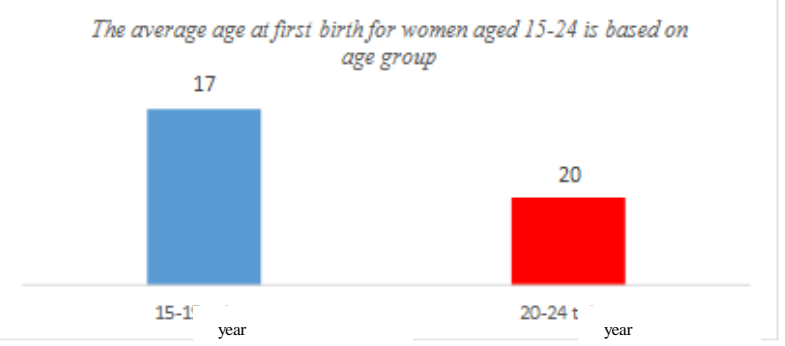

\section{Graph 3 Average First Age Childbirth Based on Age Group}

AFM (First Marriage Age)

The average age at first birth for women aged 15-24 is based on the age of first marriage, as shown in Figure 4. AFM that is getting younger will be related to the average age at first birth which is getting younger as well. It was evident that the 12-14 year AFM group had a majority of the first age at delivery of 16 years, while the 15-19 years AFM group had a higher average age of first birth giving 19 years. Next, the AFM group of 20-24 years also has a higher average age of first childbirth to 22 years.

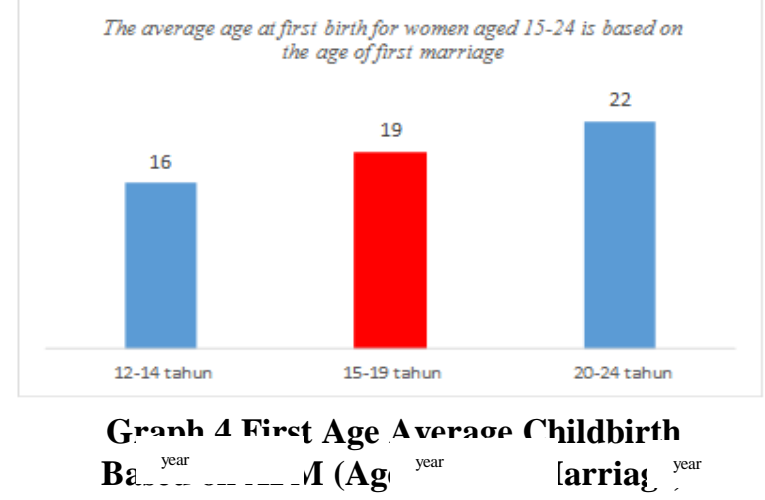

\section{Marriage Status}

Graph 5 illustrates the first age average for giving birth to women aged 15-24 years based on marital status. Unmarried respondents certainly do not have the average age at first birth. Married women have an average age of first birth at 19 years, higher than those who are divorced and separated. Women who experience divorce usually carry out early marriages as well as young childbearing age, because adolescents on the psychological side have not been able to carry out the responsibility to act as parents. It is evident that women aged 15-24 who are divorced and separated have an average age at first birth of 18 years and 17 years.

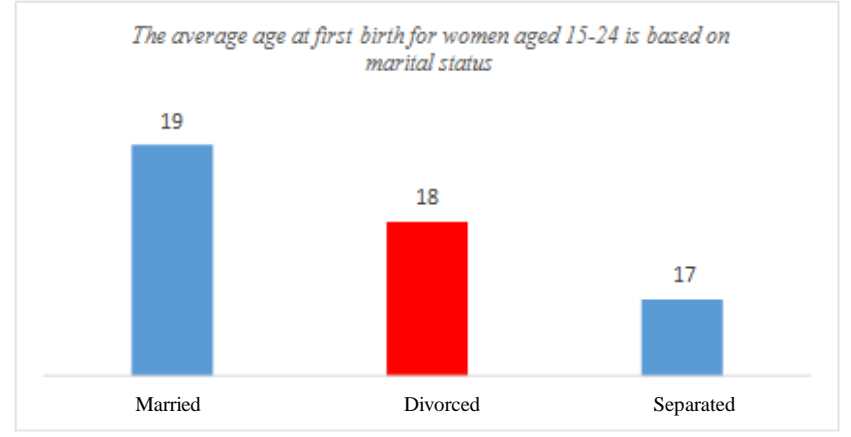

Graph 5 First Age Average Childbirth Based on Marriage Status 


\section{Factors Determining First Birth Age At East Jawa Province}

\subsubsection{Number of Children}

The number of children is classified into 0-1 children and 2-3 children. Graph 6 illustrates the average age at first birth for women aged 15-24 based on the number of children born. Women who have a number of children 0-1 have an average age of first childbirth is 20 years. Women who have children 2-3 children, then the average age at first birth is 19 years. Thus, the more the number of children born, the greater the chance for marriage at a younger age, so that the first age gives birth in adolescence.

\section{The average age at first birth for women aged 15-24 is based on the number of children born (CEB)}

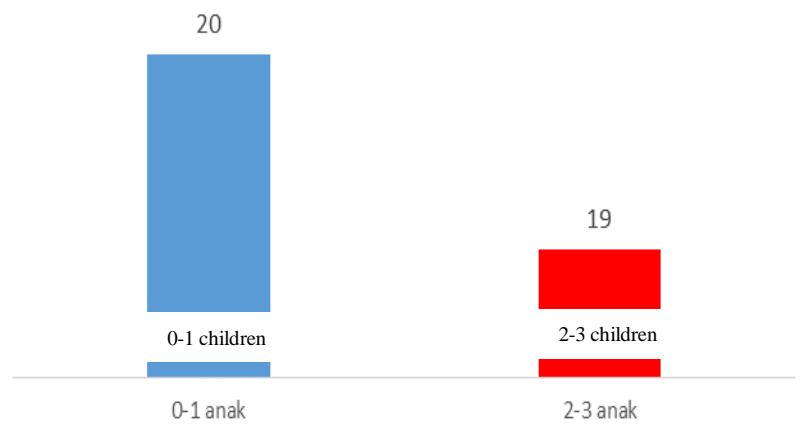

\section{First Sex Age}

Graph 6 First Age Average Childbirth Based on the number of children

Based on Figure 7 shows that the experience of having sex at the age of adolescents, then most likely first pregnancy in adolescence as well. Conversely, women who have sex at a more mature age tend to give birth first in adulthood. Based on the findings, women who had sex at the age of 11-14 years, the average age at first gave birth to 16 years. Women who have sex are more mature at the age of 15-19 years and 20-24 years of age at first give birth 19 years and 22 years.

\section{The average age at first birth for women aged 15-24 is based on the age of first sex}

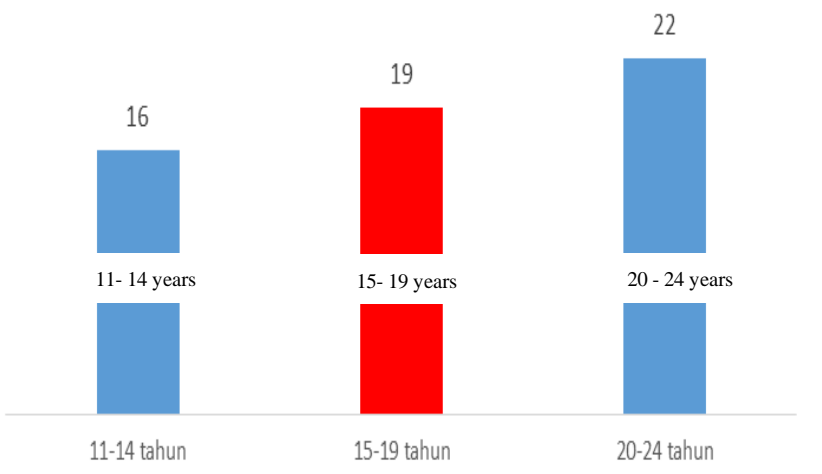

\section{Graph 7 First Age Average Childbirth Based on First Sex Age}

\section{Contraceptive Use Status and Type}

Graph 8 will summarize the average age at first birth for women aged 15-24 years based on contraceptive use status. Women aged 15-24 who do not use contraception and who use contraception, the average age at first birth is 20 years and 19 years. The older the childbirth age, they tend not to use contraception.

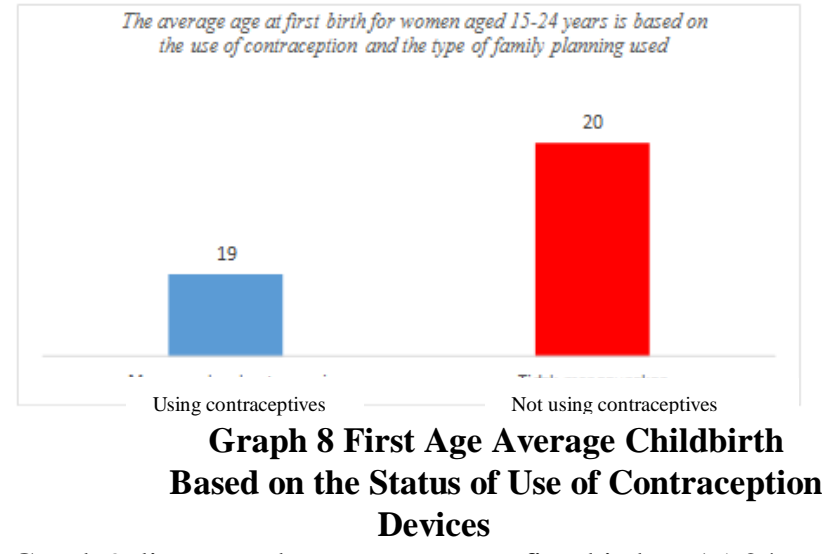

Graph 9 discusses the average age at first birth at 15-24 years based on the type of contraception used. Women who use traditional contraception tend to have a higher average age at first birth than women who use modern contraception. Traditional contraceptive users have a first age of 20 years on average, while modern contraceptive users have an average age of 19 years.

$$
\begin{gathered}
\text { The average age at first birth for women aged 15-24 years is based on the } \\
\text { use of contraception and the type of family planning used }
\end{gathered}
$$

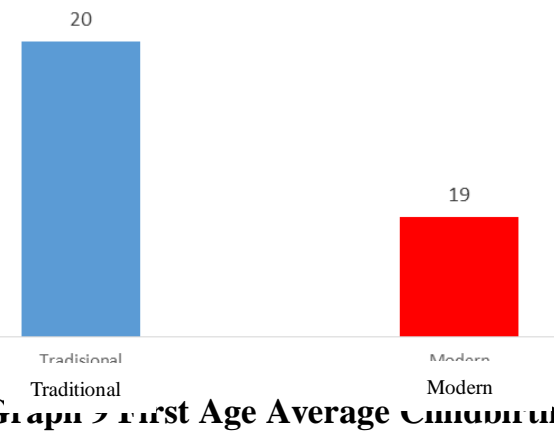

Based on the type of contraception

Women who use KB pills, injections and implants give birth on average at the age of 19 years. The majority of IUD users and interrupted intercourse were used for women on the first age of 20 years. Finally, the majority of women who use condoms are used by women who have an average age of 21 years. The full picture of the average age at first birth for women age 15-24 based on contraceptive methods / methods is summarized as Graph 10.

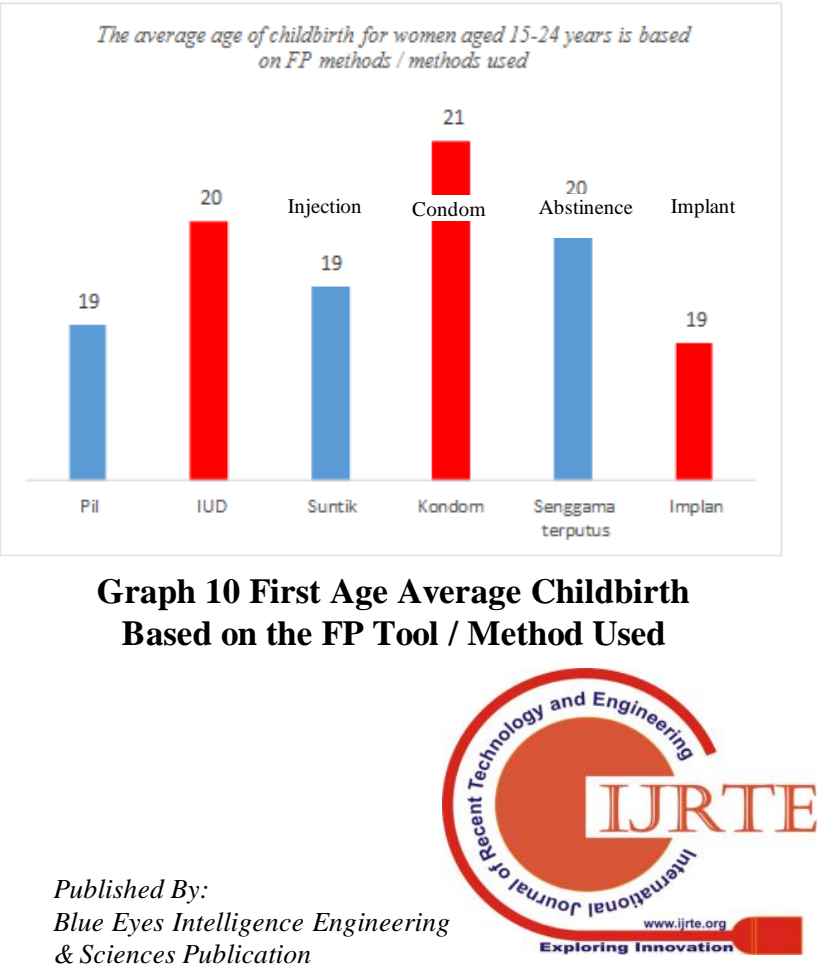




\section{d. Social Factors}

\section{Education}

Education is classified into three, namely basic education, secondary education and higher education. Women aged 15-24 who have primary / secondary and secondary / secondary education have an average age of first birth at 18 years and 20 years. The next result was that women who were highly educated had a majority of the first age at birth for 22 years. The higher education tends to be the greater the time spent in the world of education and career. So that the higher AFM tends to be potentially the first age to give birth more mature.

The average age at first birth for women aged 15-24 is based on education

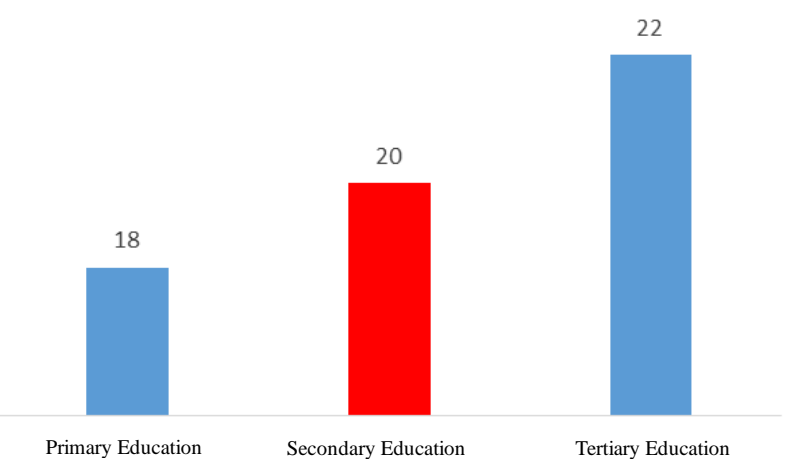

Graph 11 First Age Average Childbirth Based on education

Based on Graph 12 about the average age of first childbirth for women aged 15-24 years based on work status and the first occupational group the first age gave birth to women aged 15-24, while those who did not work were 19 years. In contrast to those who work in the professional field the average age of first childbirth is 21 years, higher than those who work in the non-professional field of 19 years. This finding shows that women belonging to the group not working and working in the non-professional sector tend to be the first to give birth at an increasingly young age. In contrast to the group of women who work in the professional sector, the majority are highly educated and well-established careers so that childbearing age is more mature.

The average age at first birth for women aged 15-24 years is based on work status and work group

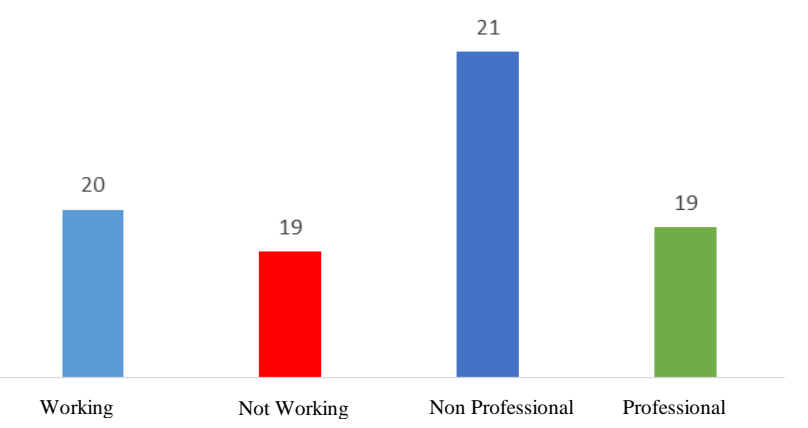

Graph 12 First Age Average Childbirth

Based on Working Status and Employment Groups

\section{e. Economic Factors}

\section{Quintile Wealth Index}

Graph 13 illustrates the average age at first birth at age 15-24

based on the wealth quintile index. The quintile wealth index

\section{Working Status and Working Group}

is used as an income variable approach which is divided into 5 , namely the lowest, middle to lower, middle, upper middle and upper middle. Overall, the higher the wealth quintile index, the more potential for the first age of childbirth to mature. In the lowest quintile wealth index group and the lowest middle age, the average age at first gave birth at 19 years. Women in the middle, upper and upper middle quintile wealth index groups have an average woman giving birth to the first 20 years of age. The higher economic status tends to give birth to a more mature age.

\section{The average age at first birth for women aged 15-24 is based on} wealth of quintiles

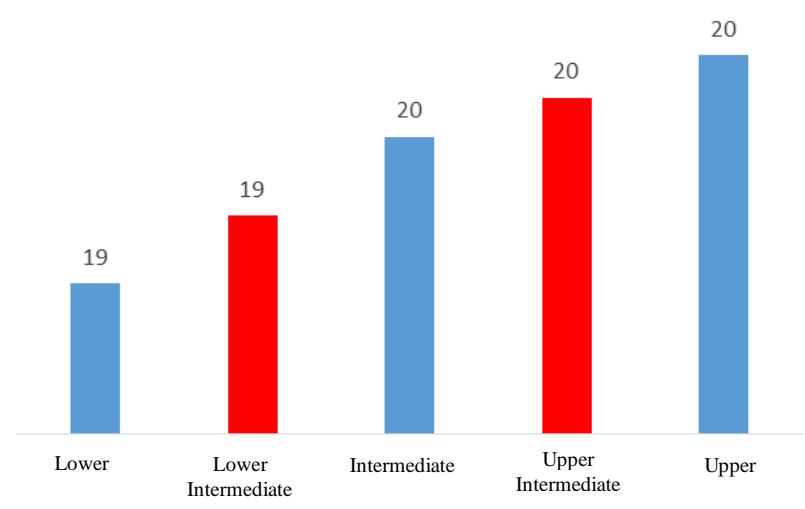

Graph 13 First Age Average Childbirth Based on the Quintile Wealth Index

\section{f. Other Factors Region and Migration Status}

The area is the area where the respondent lives, classified into: rural and urban areas. Women who live in rural areas have an average age at first birth that is younger at 19 years, or lower than those who live in cities that first gave birth at the age of 20 years. Migration is classified as: migrants and non-migrants. Women who live in the place of birth or not migrate have a younger age of first birth (19 years) than those who migrate for 20 years. The average age at first birth for women aged 15-24 based on the area of residence and migration status is reflected in Graph 14.

\section{The average age at first birth for women aged 15-24 is based on the area of residence and migration status}

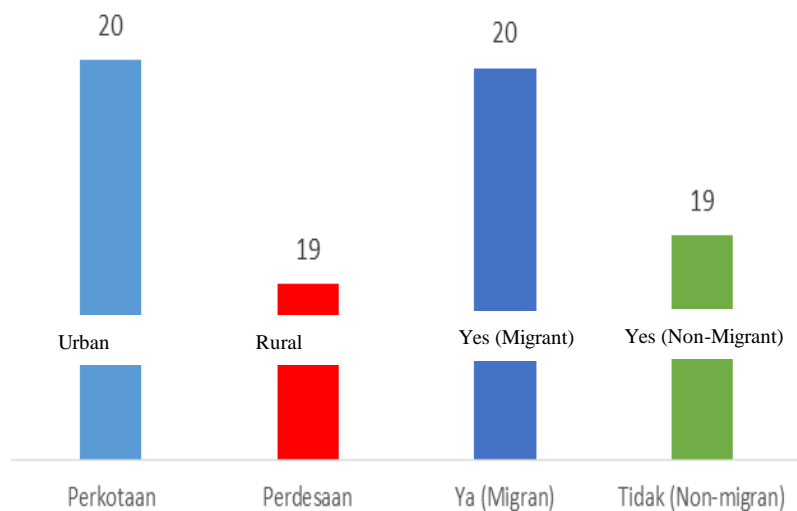

Graph 14 First Age Average Childbirth By Region and Migration Status 


\section{Factors Determining First Birth Age At East Jawa Province}

\section{CONCLUSION}

\section{Summary}

1. The average age at first birth in women 15-24 years in East Java is 19.36. This number is ranked in the top eight nationally.

2. The average age of first childbirth which is above East Java Province, among others, Province D.I. Yogyakarta, Riau Islands Province, Banten Province, Aceh Province and North Sumatra Province. For other provinces in Java, East Java Province is ranked third after Province D.I. Yogyakarta. 3. Characteristics of the first childbirth of adolescents, among others, the category age group 20-24 years, age of first marriage 12-14 years, separated status, number of children 2-3 children, age of first sex 11-14 years, using a type of modern contraception (pill, injections and implants), primary / primary education, not working, poor (lowest and lowest middle) economic status, living in the countryside and not migrating.

4. Characteristics of the first adult women giving birth, among others, the age group 15-19 years, the age of first marriage 20-24 years, married status, the number of children 0-1 children, the first sex age 20-24 years, not using contraception / family planning and if using traditional types of contraception, highly educated, working in professional types of work, economic status not poor (middle, upper and upper middle class), living in urban areas and migrating.

\section{Recommendation}

1. Efforts to expand 12-year compulsory education in marginalized areas, far from access to infrastructure and means of transportation in an effort to increase school participation and maturation of marital age.

2. Optimizing the targeted socialization of the GenRe program for the younger generation especially for women with secondary education.

3. Acceleration and distribution of education with "Reproductive Health" for young adolescents, especially in targeted areas of $\mathrm{KB}$ villages or rural areas.

4. Establish family-friendly services to invite participation of young married women.

5. Increasing and disseminating information through new entrepreneurial groups to the youths in areas with less developed economies.

6. Preventive strategies to prevent child marriage, through education (capacity building / ToT) and reproductive health. Curative strategies for child marriage actors and their parents, through parenting services and life skill development (economic empowerment).

\section{REFERENCE}

1. Adhikari, R. 2010. Demographic, socio-economic, and cultural factors affecting fertility differentials in Nepal. BMC pregnancy and childbirth, 10(1), 19-25

2. BKKBN. (2018). Survei Demografi dan Kesehatan Indonesia 2017. Jakarta: BKKBN.

3. Bongaarts, Jhon. 1978. A framework for analyzing the proximate determinants of fertility. Population and development review, 105-132.

4. Davis, Kingsley, dan Judith Blake. 1956. Social structure and fertility: An analytic framework. Economic development and cultural change, 4(3), 211-235.

5. Freedman, R. 1975. The Sociology of Human Fertility. Irvington, New York.

6. Glasier, A. \& Gebbie, A. 2005. Keluarga Berencana \& Kesehatan Reproduksi. EGC: Jakarta.
7. Lloyd, C.B. and National Research Council and Institute of Medicine 2005. Growing up global: The changing transitions to adulthood in developing countries. Panel on transitions to adulthood in developing countries. Washington D.C.: The National Academies Press.

8. Matthew, et al. 2012. Modeling the Determinants of Fertility among Women of Childbearing Age in Nigeria: Analysis Using Generalized Linear Modeling Approach. International Journal of Humanities and Social Scienc, Vol. 2(18), 167-176.

9. McLanahan, S. 2004. Diverging destinies: How children are faring under the second demographic transition. Demography 41(4): 607-627. doi:10.1353/ dem.2004.0033.

10. Rychtarikova, J., C. Gourbin and G. Wunsch. 2004. Paternal age and child death: The stillbirth case. European Journal of Population, 20(1) 23-33.

11. Sri, H. 2010. Fertilitas: Dasar-Dasar Demografi. Jakarta: Lembaga Demografi Fakultas Ekonomi UI.

12. Todaro Michael P. dan Stephen C.Smith. 2012. Pembangunan Ekonomi. Edisi Kesembilan. Jakarta: Erlangga.

13. UNICEF. 2008. The State of the World's Children 2009. New York: United Nations Children's Fund.

14. Woyanti, Nenik. 2005. Analisis Faktor-Faktor yang Mempengaruhi Permintaan Kontrasepsi di Kota Semarang. Jurnal Dinamika Pembangunan Vol. 2 No. 1: p 40-56. 